\title{
Discussion: Revisiting the concept of inter-granular void ratio in view of particle packing theory
}

\author{
C. S. CHANG*, Y. DENG $\dagger$, M. GOUDARZY $\$$, M. M. RAHMAN§ and T. WICHTMANN
}

ICE Publishing: all rights reserved

\section{CONTRIBUTION BY MEISAM GOUDARZY, MD. MIZANUR RAHMAN AND TORSTEN WICHTMANN} The authors have presented an alternative way - that is, methods A and C in the original paper (Chang \& Deng, 2019), to estimate the fraction of active fines content, $b$, in a sand -fines mixture, $b$ is the parameter to determine equivalent granular void ratio, $e^{*} . e^{*}$ is known to correlate many observed behaviour for a range of sand-fines mixtures - for example, small strain modulus, $G_{\max }$ (Rahman et al., 2012; Goudarzy et al., 2017), critical state line, CSL (Thevanayagam et al., 2002; Rahman et al., 2008), instability line or dilatancy. Furthermore, $e^{*}$ has been applied in constitutive modelling (Lashkari, 2014; Rahman et al., 2014). Therefore, any contribution to $e^{*}$ or $b$ parameter is welcome. While this alternative way was derived from some interesting thoughts, it may be enriched with a further discussion.

The authors have reviewed the earlier work of the contributors; however, an error in the presentation was noted that must be corrected to avoid confusion. The following are the contributors' thoughts that may be considered to further improve the model.

\section{EFFECT OF $F_{\mathrm{C}}$ ON $B$ PARAMETER}

The effect of $f_{\mathrm{c}}$ on the $b$ parameter was evaluated in Figs. 3(a) and 3(b) in the original publication in $e-f_{\mathrm{c}}$ plot. With an approximately linear relation between $e$ and $f_{\mathrm{c}}$ for $f_{\mathrm{c}}<f_{\text {thre }}$, it is assumed that $b$ is independent of $f_{\mathrm{c}}$. The contributors believe this approximation should be improved due to the following reasons.

- The quality of the linear approximation decreases towards the higher $f_{\mathrm{c}}$ and $d / D$, which is acknowledged as a secondary effect. While both $e_{\mathrm{g}}$ and $e^{*}$ works reasonably well for lower $f_{\mathrm{c}}$, we believe a good estimation of $b$ for higher $f_{\mathrm{c}}$ is more important for applying $e^{*}$ in the equivalent state theory (Barnett et al., 2020). The quality

Manuscript received 30 October 2020; accepted 3 December 2020.

Published online at www.geotechniqueletters.com on 15 December 2020.

*Department of Civil and Environmental Engineering, University of Massachusetts, Amherst, MA, USA

(Orcid:0000-0002-3595-5099).

†Department of Civil and Environmental Engineering, University of Massachusetts, Amherst, MA, USA

(Orcid:0000-0001-5343-1988).

$\$$ Soil Mechanics, Foundation Engineering and Environmental Geotechnics, Ruhr-Universität Bochum, Bochum, Germany.

§UniSA STEM (Science, Technology, Engineering and Mathematics) University of South Australia, Mawson Lakes, Australia. of the linear approximation may further reduce for increasing $f_{\text {thre }}$ with increasing $d / D$ (in Fig. 3(b)) which is a common observation (Rahman et al., 2009; Lashkari, 2014).

- $b=0$ at low $f_{\mathrm{c}}$ is well accepted. However, a constant $b$ value irrespective of $f_{\mathrm{c}}<f_{\text {thre }}$ means that the model does not allow to consider the increasing portion of the active fines in the sand-fines mixture with increasing fines content - that is, $b$ jumps from zero to a high constant value even with a very small $f_{\mathrm{c}}$ of $0 \cdot 001$. With a series of discrete-element simulations for sand with up to $f_{\mathrm{c}}=0 \cdot 20$, Barnett et al. (2020) showed that the deviatoric stress contribution of fines increases with $f_{\mathrm{c}}$ - that is, $b$ depends on $f_{\mathrm{c}}$.

An appropriate non-linear approximation of the relationship $b\left(f_{\mathrm{c}}\right)$ may remove these issues and could be considered in the future works.

\section{DETERMINATION OF $V_{F}, V_{C}$ AND $S$}

$v_{\mathrm{f}}$ and $v_{\mathrm{c}}$ in equation (12) were determined from the CSLs for fines and sand, respectively - that is, these CSLs have to be known. Further, $s$ was back-analysed for the best-fit equivalent granular CSL in methods A and C (Chang \& Deng, 2019), which is a bit more complicated back analysis approach than method B (Thevanayagam et al., 2002). The contributors emphasise that method D (Rahman \& Lo, 2008) was the only model in this study that can estimate $b$ using simple input parameters - that is, $f_{\mathrm{c}}$ and particle diameter ratio.

To further evaluate methods $\mathrm{C}$ and $\mathrm{D}$, in the original paper, the current discussion considers $G_{\max }$ data for Hostun sand with $f_{\mathrm{c}}=0 \cdot 05,0 \cdot 10,0 \cdot 20,0 \cdot 30$ (quartz powder) (Goudarzy et al., 2017). The effect of $f_{\mathrm{c}}$ on $G_{\max }$ is shown in Fig. 9(a). To evaluate method C, $s$ was varied from 2 to 8 to get a best-fit trend as the suggested range in Fig. 2 of the original publication. The results for $s=2$ and $s=8$ are shown in Figs 9(b) and 9(c), respectively. In both cases, a clear deviation is observed for higher $f_{\mathrm{c}}$ of 0.30 , which is associated with the discussion above. Method D was also used without any back analysis and the correlation is shown in Fig. 9(d).

Note that, it must be noted that unlike Table 1 in the original paper, Goudarzy et al. (2016) used Rahman's Equation (Rahman \& Lo, 2008) to estimate $b$. They did not propose a new Equation to estimate $b$. Goudarzy et al. (2016) showed that the predicted $G_{\max }$ using $e^{*}$ can be improved with further calibration of the constant parameter in Rahman's Equation, method D in original paper.

\section{AUTHORS' REPLY}

The authors thank the contributors for their interest and the points they raised pertaining to the discussed paper (Chang \& Deng, 2019). The points are mainly related to: $(a)$ the effect of fines content on the $b$ parameter 


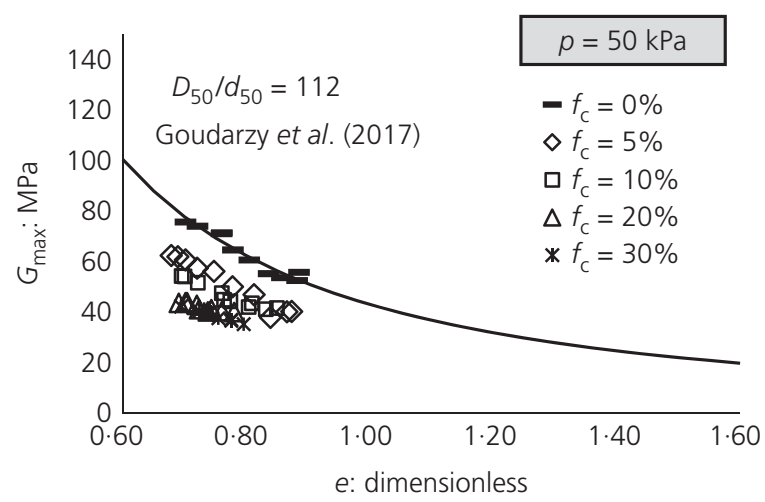

(a)

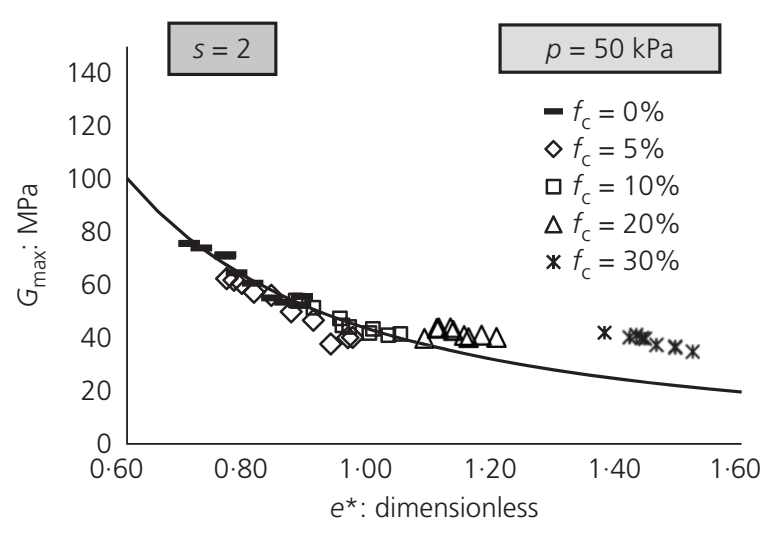

(b)

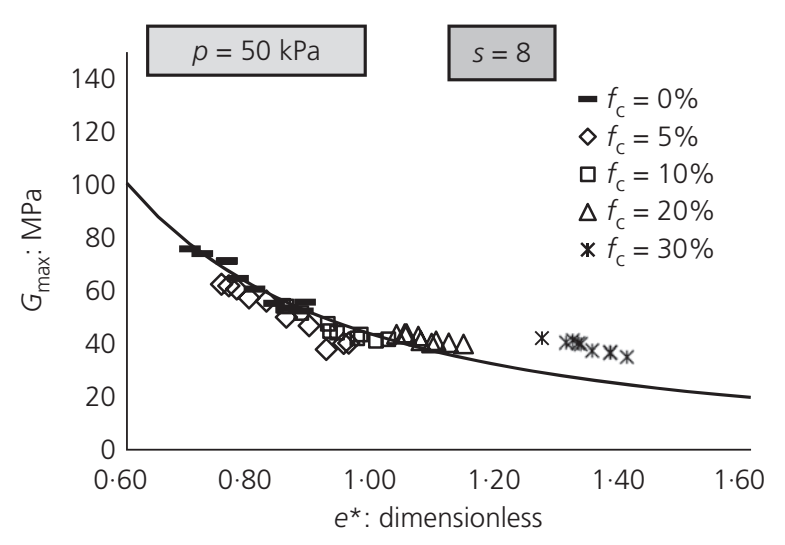

(c)

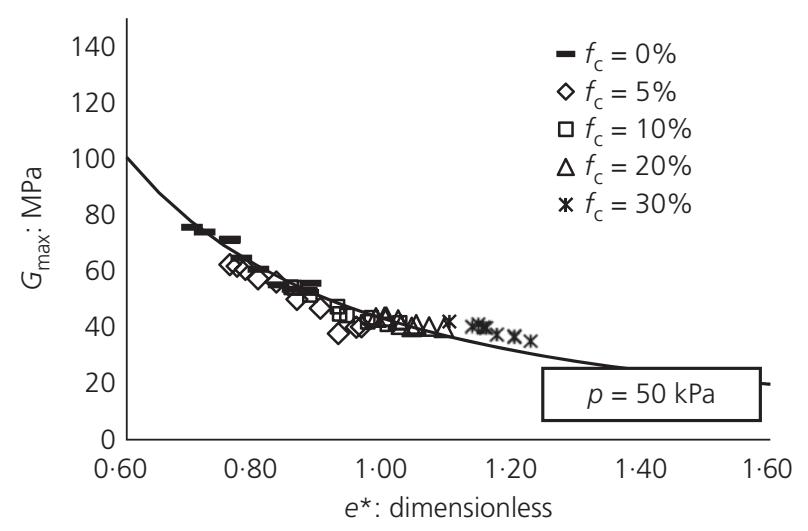

(d)

Fig. 9. (a) Effect of fines content on $G_{\max }$ in Hostun sand + quartz powder (Goudarzy et al., 2017); (b) and (c) $G_{\max }-e^{*}$ using method C in the original paper with $S=2$ and $S=8$ and (d) $G_{\max }-e^{\star}$ using method $D$ in the original paper without any back analysis and $(b)$ methods $\mathrm{A}$ and $\mathrm{C}$ proposed in the original paper (Chang \& Deng, 2019). Next, clarifications for these points are provided as follows.

\section{Effect of fines content on the $b$ parameter}

The first point raised by the contributors is related to the effect of fines content $f_{\mathrm{c}}$ on the $b$ parameter.

In the concept of inter-granular void ratio, the $b$ parameter is defined as the fraction of fines that contributes to the active inter-grain contacts or to the force structure. According to this elusive definition, the value of $b$ is not a measurable quantity. In this paper, based on a particle packing theory, the $b$ parameter is found to be linearly related to the slope of the line in the $e-f_{\mathrm{c}}$ plot for $f_{\mathrm{c}}<f_{\text {thre }}$ (i.e. coarse-particle dominant region). By this relation, $b$ becomes a measurable quantity. According to Chang \& Deng (2020), for binary mixtures with small particle-size ratios (e.g. $d_{50} / D_{50}=0 \cdot 06-0 \cdot 16$ ), the experimental data show that linear approximation for the curves is a good assumption (see Fig. 10). In this case, the slope is a constant for the coarse-particle dominant region. Since the slope is independent of fines content, consequently, the value of $b$ is independent of $f_{\mathrm{c}}$.

In addition, for binary mixtures with large particle-size ratios (e.g. $d_{50} / D_{50}=0.25-0.43$ ), the experimental curves show a non-linear feature (see Fig. 11). Thus, the value of $b$ is dependent on $f_{\mathrm{c}}$. However, for the non-linear curves, the linear assumption is reasonably adequate to describe the first part of the curve $(<20 \%)$ in the coarse-particle dominant region. The effect of fines content in the region of $20-35 \%$ can be regarded as secondary.

To model the non-linear feature in a better way in the region of $f_{\mathrm{c}}=20-35 \%$, the authors have developed a non-linear particle packing model, which captures the non-linear characteristics of $e$ against $f_{\mathrm{c}}$ (Chang \& Deng, 2018, 2017). The solid lines in Figs. 10 and 11 indicate predictions by using the non-linear model.

However, from a theoretical point of view, it may not be adequate to attempt finding the values of $b$ in the region of $f_{\mathrm{c}}=20-35 \%$. It is noted that the concept of inter-granular void ratio is based on the hypothesis that, for an equivalent inter-granular void ratio, the mechanical behaviour of a binary mixture is identical to a 'pure coarse-particle packing'. This hypothesis is only applicable when the packing structure of the binary mixture is similar to the 'pure coarse-particle packing'. This means that the binary mixture must be in a 'coarse-particle dominant packing' condition, generally with a low fines content.

However, for the region of $f_{\mathrm{c}}=20-35 \%$, the amount of fines have largely filled the voids between coarse particles and substantially altered the coarse-particle network (Chang \& Deng, 2017). Thus, the packing structure is no longer in a coarse-particle dominant condition, it could even be in a fine-particle dominant condition as shown for some mixtures in Figs. 10 and 11.

Another point raised by the contributors is regarding the value of parameter $b$ at low $f_{\text {c }}$. They believe that parameter $b$ should be zero at low $f_{\mathrm{c}}$, and the value of $b$ then increases with the increase of fines content. This supposition may not be valid. Considering only a single fine-particle, added to a coarse-particle packing, is wedged in between two coarse particles. Although this single particle contributes very little in carrying the load, but the particle is still active. Thus, by definition, the value of $b$ should be 1 instead of zero. This situation is more evident if the size of the single fine particle is close to the size of coarse particles. The large-size fine particle, unable to fit into the void, is inevitably an active particle having contact with 

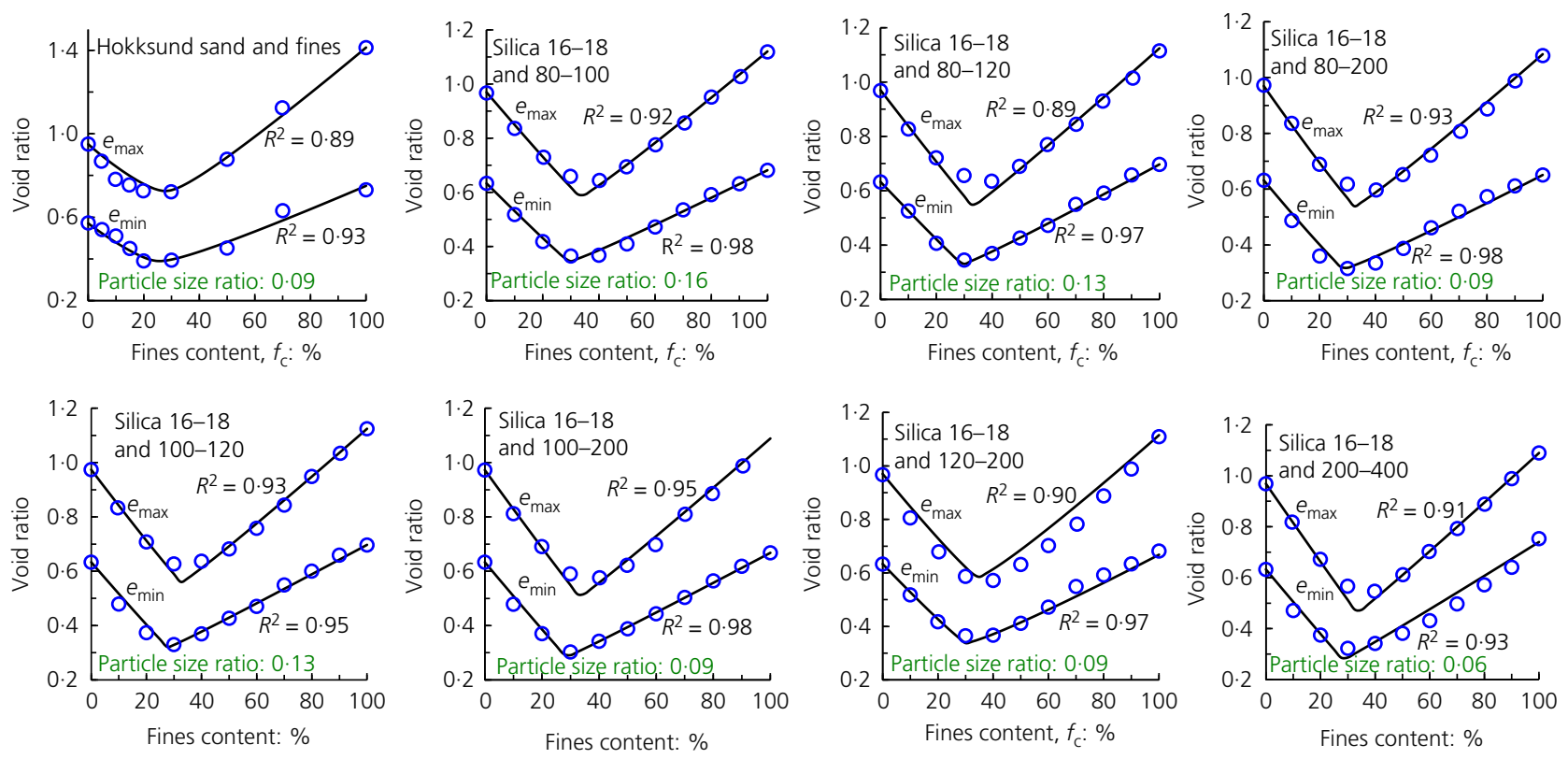

- Experimental results

Prediction using the model proposed by Chang \& Deng (2017)

Fig. 10. Plots of minimum or maximum void ratio against fines content for the binary mixtures with small particle-size ratios (0.09-0.16): the experimental data for Hokksund sand and fines were obtained from Yang (2004); the experimental data for silica 16-18 and 80-100, silica 16-18 and 80-120, silica 16-18 and 80-200, silica 16-18 and 100-120, silica 16-18 and 100-200, silica 16-18 and 120-200 and silica 16-18 and 200-400 were obtained from Yilmaz (2009)
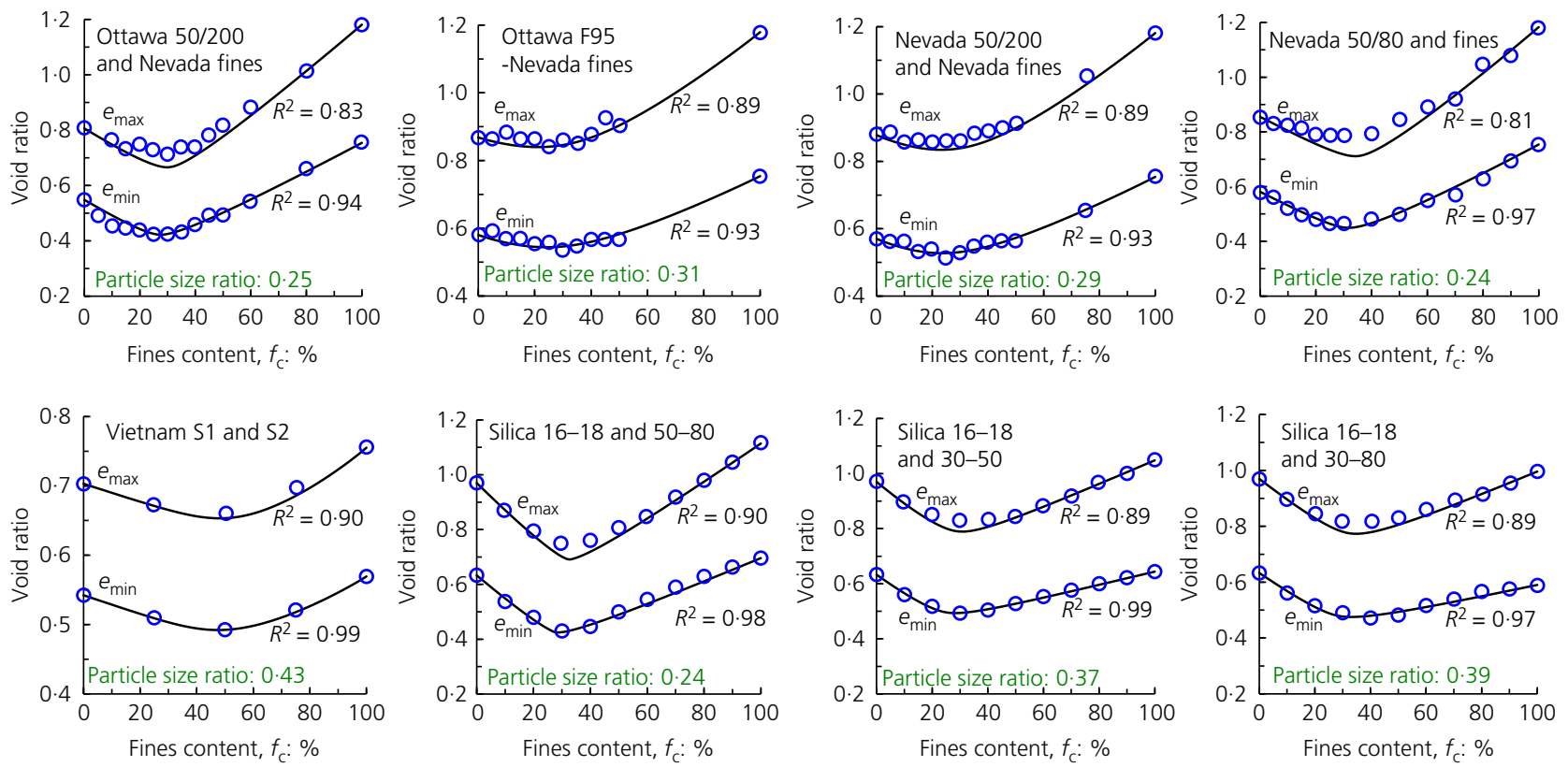

- Experimental results

Prediction using the model

proposed by Chang and Deng (2017)

Fig. 11. Plots of minimum or maximum void ratio against fines content for the binary mixtures with large particle-size ratios (0.24-0.43): the experimental data for Ottawa 50/200 and Nevada fines and Ottawa F95 and Nevada fines were obtained from Lade \& Yamamuro (1997); the experimental data for Nevada 50/200 and Nevada fines and Nevada 50/80 and fines were obtained from Lade et al. (1998); the experimental data for Vietnam S1 and S2 were obtained from Cho (2014); the experimental data for silica 16-18 and 50-80, silica 16-18 and 30-50 and silica 16-18 and 30-80 were obtained from Yilmaz (2009)

neighbouring coarse particles. Thus, the value of $b$ should not be zero. Hence, although the fine content is very low, and the contribution of the small quantity of fines is negligible in terms of carrying load, but a portion of the fines may be active. As a result, the value of $b$ is not necessarily zero from the physical point of view. 
This can also be explained from a mathematical point of view. With the definition of the equivalent inter-granular void ratio

$$
e_{\mathrm{c}}^{*}=\frac{e+(1-b) f_{\mathrm{c}}}{1-(1-b) f_{\mathrm{c}}}
$$

as fines content approaches zero, the equivalent inter-granular void ratio $e_{\mathrm{c}}^{*}$ is equal to the void ratio $e$ of the coarse-particle packing, regardless of the values of $b$. Therefore, the parameter $b$ does not have to be zero at low $f_{\mathrm{c}}$.

\section{Methods $A$ and $C$ proposed in the original paper}

The second point raised by the contributors is regarding the parameters required in method A proposed in this paper, which need to be calibrated from test results. This method is cumbersome compared to method $\mathrm{D}$, which requires only two simple input parameters, $f_{\mathrm{c}}$ and the particle-size ratio.

The purpose of this study was not to provide another empirical equation. The authors intended to analyse the concept of inter-granular void ratio from the viewpoint of particle packing theory and provide a better insight into $e_{\mathrm{c}}^{*}$ and the parameter $b$. According to the particle packing theory, the parameter $b$ is related to physical properties of $v_{\mathrm{f}}$ and $v_{\mathrm{c}}$ (i.e. the specific volumes of pure fine particles and pure coarse particles, respectively), which entails calibration from the materials of the binary mixture.

For practical application, in the region of low fines content, under a specific condition $v_{\mathrm{f}}=v_{\mathrm{c}}$, the effect of material difference can be cancelled. Hence, a simplified $b$ equation (method $\mathrm{C}$ ) is proposed

$$
b=1-\left(1-d_{50} / D_{50}\right)^{s}
$$

where the exponent $s$ is a parameter dependent on particle shape. The parameter $s$ is suggested to be calibrated from test results of the binary mixture. However, if one wants to avoid any experimental tests, the value of $s$ can be estimated by the particle shape of the materials of the binary mixture (see Fig. 11 in Chang \& Deng, 2020).

Equation (17) was used by the contributors, applying the concept of inter-granular void ratio, to predict the values of the maximum shear modulus $G_{\max }$ of binary mixtures (Huston sand and quartz powder). They have shown that equation (17) generally fits the test results well of $G_{\max }$ for $f_{\mathrm{c}}=0,5,10,20 \%$. However, it does not fit $f_{\mathrm{c}}=30 \%$. The authors do not expect that the simplified equation (17) can fit the test results of $G_{\max }$ for $f_{\mathrm{c}}=30 \%$, since this equation is derived from the condition of low fines content. Also, the authors believe that at $f_{\mathrm{c}}=30 \%$, the mixture is no longer in the coarse-particle dominant condition. Feasibly, the mixture may even be in the fine-particle dominant condition. The concept of inter-granular void ratio may not be applicable for this condition.

\section{REFERENCES}

Barnett, N., Rahman, M. M., Karim, M. R., Nguyen, H. B. K. \& Carraro, J. A. H. (2020). Equivalent state theory for mixtures of sand with non-plastic fines: a DEM investigation. Géotechnique 1-18, https://doi.org/10.1680/jgeot.19.P.103.

Chang, C. S. \& Deng, Y. (2017). A particle packing model for sandsilt mixtures with the effect of dual-skeleton. Gran. Matter 19, 80. https://doi.org/10.1007/s10035-017-0762-1.

Chang, C. S. \& Deng, Y. (2018). A nonlinear packing model for multi-sized particle mixtures. Powder Technol. 336, 449-464.

Chang, C. S. \& Deng, Y. (2019). Revisiting the concept of inter-granular void ratio in view of particle packing theory. Géotech. Lett. 9, No. 2, 121-129, https://doi.org/10.1680/jgele. 18.00175 .

Chang, C. S. \& Deng, Y. (2020). Packing potential index for binary mixtures of granular soil. Powder Technol. 372, 148-160.

Cho, Y. T. (2014). The study of GCTS triaxial apparatus function and mixing sand void ratio. Master Thesis, National Taiwan University, Taipei, Taiwan.

Goudarzy, M., Rahman, M. M., König, D. \& Schanz, T. (2016). Influence of non-plastic fines content on maximum shear modulus of granular materials. Soils Found. 56, No. 6, 973-983.

Goudarzy, M., Rahemi, N., Rahman, M. M. \& Schanz, T. (2017). Predicting the maximum shear modulus of sands containing non-plastic fines. J. Geotech. Geoenviron. Engng 143, No. 9, 1-5.

Lade, P. V. \& Yamamuro, J. A. (1997). Effects of nonplastic fines on static liquefaction of sands. Can. Geotech. J. 34, 918-928. https://doi.org/10.1139/t97-052.

Lade, P. V., Liggio, C. D. \& Yamamuro, J. A. (1998). Effects of non-plastic fines on minimum and maximum void ratios of sand. Geotech. Test. J. 21, No. 4, 336-347. https://doi.org/10. 1520/GTJ11373J.

Lashkari, A. (2014). Recommendations for extension and re-calibration of an existing sand constitutive model taking into account varying non-plastic fines content. Soil Dyn. Earthq. Engng 61-62, 212-238.

Rahman, M. M. \& Lo, S. R. (2008). The prediction of equivalent granular steady state line of loose sand with fines. Geomech. Geoeng. 3, No. 3, 179-190.

Rahman, M. M., Lo, S. R. \& Gnanendran, C. T. (2008). On equivalent granular void ratio and steady state behaviour of loose sand with fines. Can. Geotech. J. 45, No. 10, 1439-1456.

Rahman, M. M., Lo, S. R. \& Gnanendran, C. T. (2009). Reply to the discussion by Wanatowski and $\mathrm{Chu}$ on 'Onn equivalent granular void ratio and steady state behaviour of loose sand with fines'. Can. Geotech. J. 46, No. 4, 483-486.

Rahman, M. M., Cubrinovski, M. \& Lo, S. R. (2012). Initial shear modulus of sandy soils and equivalent granular void ratio. Geomech. Geoengng 7, No. 3, 219-226.

Rahman, M. M., Lo, S. C. R. \& Dafalias, Y. F. (2014). Modelling the static liquefaction of sand with low-plasticity fines. Géotechnique 64, No. 11, 881-894.

Thevanayagam, S., Shenthan, T., Mohan, S. \& Liang, J. (2002). Undrained fragility of clean sands, silty sands, and sandy silts. J. Geotech. Geoenviron. Engng 128, No. 10, 849-859.

Yang, S. L. (2004). Characterization of the properties of sand-silt mixtures. Norwegian University of Science and Technology.

Yilmaz, Y. (2009). A study on the limit void ratio characteristics of medium to fine mixed graded sands. Engng Geol. 104, No. 3-4, 290-294. https://doi.org/10.1016/j.enggeo.2008.11.009. 